\title{
Multilingual International Students at a Canadian University: Portraits of Agency
}

\author{
Vander Tavares ${ }^{1}$ \\ York University, Canada
}

\begin{abstract}
This paper draws on the theoretical concepts of individual agency and academic buoyancy to explore the ways in which three multilingual international students responded to and overcame the challenges they encountered while studying at a university in Canada. This investigation is situated within and against the discourses of deficit and disruption that have traditionally surrounded the accounts of international students who use English as an additional language (EAL) in institutions of higher education. Methodologically conceptualized through the lens of portraiture, which focuses on identifying goodness in participants, this paper presents the portraits of the three students with an attention to the physical and sociocultural contexts where the students were embedded. Individual semi-structured interviews and observations of the host institution were conducted in order to gain an in-depth understanding of the students' experiences. Findings indicate that the students' challenges were complex, found primarily in the linguistic, academic, and social dimensions, and originating from both structural and individual factors. Simultaneously, the students strategized and employed agency by seeking support in conventional and alternative ways and by refusing to conform to institutional expectations. This paper is concluded with a discussion about the importance of considering the context when examining multilingual international student agency.
\end{abstract}

KEYWORDS: Agency, ESL, Higher Education, International Students, Multilingual, Portraiture.

Over the last decade, Canadian universities have seen a substantial growth of the overall international student population. Several recent political events and sociocultural trends have collaboratively played a key role in the foregrounding of Canada as a prominent destination for international students. For instance, the past presidency of Donald Trump in the United States and the withdrawal of the United Kingdom from the European Union have influenced international students to fluctuate toward emergent destinations characterized by more political stability, such as Canada and Australia (Choudaha, 2017). Furthermore, positive structural changes to Canadian immigration policy at the federal and provincial levels have contributed to improving the retention of international students in the country following graduation (Government of Canada, 2018), which helps present Canada as an attractive environment. Based on such developments, the enrolment of international students is only expected to continue to grow in the coming years.

The vast majority of international students in Canada are multilingual speakers for whom English is not a first language. As such, the multilingual international student experience in Canada remains significantly impacted, both in theory and practice, by traditional discourses

\footnotetext{
${ }^{1}$ Corresponding Author E-mail: vanderjuniort1@gmail.com
} 
of deficit perpetuated through the conflation of non-native speakerism with intellectual and cultural inferiority (Heng, 2018; Shapiro, 2014). Additionally, the experiences of multilingual international students in higher education have been generally understood in juxtaposition with those of domestic, native-speaker students. The experiences of the latter group have been constructed as the ideal which multilingual international students are expected to embody. As a result, research has unreasonably produced a marked image of multilingual international students by universally documenting the challenges, shortcomings, and failures of the students, primarily in the domains of language and academics (Friedenberg, 2009).

A survey of the literature reveals a range of negative identities which have been imposed on multilingual international students. Generally speaking, the students are viewed prevailingly as passive, especially those of an Asian background, and detached from the classroom experience (e.g., Bartlett \& Fisher, 2011; Huang \& Cowden, 2009; Xiao, 2021). Other perceptions and discourses frame the students as antisocial (e.g., Ruble \& Zhang, 2013) and lacking critical thinking (e.g., Fell \& Lukianova, 2015). Concerningly, there are also constructions of the students as being disruptive to academia and even threats to Canadian society (e.g., Anderson, 2020; Tavares, 2021a). Such discourses directly impact the beliefs and attitudes not only of members of the host academic community, but also of multilingual international students themselves, in relation to the students' place in and contributions to higher education. While much of recent scholarship has sought to challenge such marked images, accounts specifically of agency and success continue to deserve more attention.

The purpose of this paper is to provide balanced accounts of multilingual international students' experiences. To accomplish this, this paper adopts a theoretical perspective of agency in order to contextualize the experiences of three multilingual international students at a Canadian university. More specifically, this paper is guided by the following two questions: first, what kinds of challenges did the three multilingual international students encounter at their university? Second, how did the students (attempt to) overcome them? This paper begins with a general overview of the construct of agency and progresses to situate it within research in second language education. The students' academic experiences are also seen through the lens of academic buoyancy, a more recent psychology-based concept described below. The investigation presented in this paper is informed by the methodological approach of portraiture. Recommendations follow the discussion of findings.

\section{Individual Agency}

Agency is a multifaceted concept theorized extensively across multiple disciplines. Linguistic anthropologist Ahearn (2001) defined agency as "the socioculturally mediated capacity to act" (p. 112). Bandura (2006), a social psychologist, argued that to be an agent is "to influence intentionally one's functioning and life circumstances" (p. 164) and proposed that human agency is characterized by four core properties, which will be examined in the next paragraph. In both conceptions, the highly contextual nature of being an agent becomes evident as agency is exercised and understood differently by different people relative to their subjective sociocultural positioning in life. Bandura (2006) noted that humans are not merely the product of their life circumstances. On the contrary, as agents, humans have the power to influence and shape their personal contexts.

The following conceptual properties comprise human agency: intentionality, forethought, self-reactiveness, and self-reflectiveness. Intentionality means not only having the intention to achieve something, but also the plans and strategies to make it happen. Forethought involves visualizing the future in which the expected outcomes become the guiding and motivating forces to act. Self-reactiveness relates to devising, motivating, and regulating the execution of "appropriate courses of action" (Bandura, 2006, p. 165). Finally, selfreflectiveness relates to the ability to reflect upon one's self, thoughts, and actions, and to "make 
corrective adjustments if necessary" (p. 165). Bandura (2006) believes that self-reflectiveness comprises the most uniquely human core property because it includes one's ability to selfexaminate throughout the whole course of action.

\section{Agency in Second Language Acquisition}

The construct of agency has gained considerable prominence in second language acquisition research over the last two decades. Vitanova et al. (2015) have proposed that the emergence of agency in the field is linked to the increasingly more social and sociocultural perspectives on how additional languages are learned and used. Furthermore, by exploring agency often in conjunction with identity and particularly through an analysis of discourse, the view of multilingual L2 users as passive recipients of linguistic input has evolved to recognize them as complex individuals who intentionally react to, and thus, influence, their sociocultural surroundings. Indeed, examining the sociocultural environment is indispensable to our understanding of how multilingual L2 users may employ agency. Each multilingual L2 user navigates a subjectively different language journey; accordingly, the significance of agentive acts must be understood in relation to the user's context.

Agency is fundamental for multilingual international students to grow and succeed in English-medium higher education. The academic experience presents the students novel, and oftentimes challenging, situations which require them to exercise contextualized forms of agency. Tran and Vu (2018) explained that international students' agency may be "revealed through how they think they are expected to respond... and how they personally want to respond" to the situations around them (p. 168). A perspective of agency contributes to challenging the notion of multilingual international students as passive and quiet individuals who do not strategically and reflexively respond to the challenges and threats they face. For instance, while the academic community has traditionally interpreted silence as a sign of disengagement and compliance on the part of multilingual international students, the students themselves may see it as a behavioural manifestation of resistance (Choi, 2015).

Multilingual international students may exercise agency by planning, strategizing, reflecting, and negotiating their needs. Nevertheless, the environment in which the students are embedded also centrally contributes to how (far) the effort from such agentive behaviour will translate into successful outcomes. Tran and Vu (2018) have demonstrated that "institutional forces play a crucial role in supporting or enabling students' capacity to enact agency" (p. 171). Some factors which can disempower the students from succeeding in their efforts to bring about change include the lack of sociocultural resources, support structures, and cultural diversity. As a result, agency tends to take the form of struggle (Tran \& Vu, 2018). On other occasions, individual agency that is fueled by a common desire or need can shift to collective agency in order to deal with structural issues that affect the group as a whole.

\section{Academic Buoyancy}

Academic buoyancy can be considered a more relatively recent construct within the field of positive psychology. Martin and Marsh (2008) defined academic buoyancy as "students' ability to successfully deal with academic setbacks and challenges that are typical of the ordinary course of school life" (p. 54). Academic buoyancy is conceptually related to academic resilience, though there are important differences between the two. Wu et al. (2013) have proposed that resilience represents "the capacity and dynamic process of adaptively overcoming stress and adversity while maintaining normal psychological and physical functioning" (p. 1). The focus in resilience-oriented research lays in understanding how individuals respond to and overcome much more significant experiences, such as "stressful life events, trauma, and chronic 
adversity" (p. 1). Therefore, resilience refers to situations on the more extreme side of the spectrum of difficulties.

Indeed, academic resilience is traditionally also concerned with more extreme adversity in the context of students' experiences. Previous research which has espoused an academic resilience orientation has explored student groups, particularly "chronic underachievers" or ethnic groups, in inauspicious and detrimental situations, such as in schooling characterized by conditions of poverty and gang violence (Martin \& Marsh, 2008, p. 54). Contrastingly, academic buoyancy considers the everyday hassles as well as the "ups and downs" of student life, focusing primarily on how a student may respond to the challenges they encounter. Furthermore, academic buoyancy is also concerned with the ways students cope-in other words, with students' cognitive and behavioural efforts "to deal with the problem or adversity" (p. 56). A less relevant coping response within the concept of academic buoyancy is the emotional, which examines how individuals "address the emotions of the stressful situation" (p. 56).

Academic buoyancy is conventionally determined by use of scales. However, the objective of employing the concept in this study is different. In here, academic buoyancy is intended to help rather contextualize the students' experiences with an attention to identifying potential coping strategies or patterns of success. In their qualitative study with English as a foreign language (EFL) learners, Kim et al. (2018) identified four components which contributed to the students' buoyancy in their learning: (strong) social support, emotional regulation, clear learning goals, and tenacity. The authors' findings on the role of strong social support to achieving academic buoyancy are on par with those from Martin and Marsh (2008), which included support from parents, peers, and friends, among other factors. Indeed, Arthur (2017) argues that social integration is key to international students' positive academic performance and that faculty, counsellors, and domestic students should be seen as social (re)sources of support for the students.

\section{Research Design}

This study was conceptualized through the methodological lens of portraiture. Portraiture is an approach to qualitative research pioneered by Lawrence-Lightfoot and Davis (1997). Considering its ethnographic nature, portraiture may be found primarily in research in education, sociology, and anthropology. More recently, some studies in applied linguistics have disseminated their findings through a design of "learner portraits" (e.g., Muramatsu, 2013). However, such an approach to presenting the lived experiences of multilingual students is fundamentally different from portraiture as a unified method designed not only for the presentation of findings, but also for data collection and analysis. The epistemological orientations and methodological features of portraiture productively lend themselves to research in applied linguistics, some of which are discussed below with particular reference to the concerns of this study.

One of the central features of the method is its deliberate ideological orientation to exploring and documenting success rather than failure. Lawrence-Lightfoot and Davis (1997) argue that, while failure should not be ignored or unproblematized, it should also not constitute the focus of research aimed at studying people. When focused on shortcomings, research can only (continue to) generate a distorted view of any object of study, and by extension, normalize the expectation for failure in research involving human subjects. Therefore, portraiture seeks to first find and document - through exploration, negotiation, and introspection - the goodness in the study participants in every stage of the research process. Keeping in mind that multilingual (and international) students have been often portrayed unfavourably in the research literature, this feature of the method becomes ethically important for this study. 
Additionally, similarly to the case study approach, portraiture does not see research to be possible outside of its physical, social, and cultural contexts (Lawrence-Lightfoot \& Davis, 1997). Therefore, as the portraitist weaves together the findings, they include detailed descriptions of the context in which the research took place. It is precisely for this reason that portraiture has been defined as the combination of art and science, in which the findingsproduced through rigorous scientific research methods - are presented with an attention to the aesthetic. The goal here is twofold: first, to "paint" a richly detailed portrayal of the research setting as well as of its participants, and second, to produce research that is of an artistic nature in order to reach and speak to an audience that resides outside the walls of the academy.

When analyzing and producing the findings, the portraitist draws on portraiture's concept of voice (Chapman, 2005). This concept contextualizes the multifaceted involvement of the researcher as a complex individual who brings into the research a number of previous and current experiences, knowledges, biases, intentions, and concerns about the object of study. The "layers" of voice include: voice as autobiography: the portraitist's background in (dis)connection with the sociocultural context of the site and community studied; voice as preoccupation: the portrait's concerns that fuel the investigation; voice in dialogue: the cocreation of data; voice as witness: the portraitist's individual experience, often through observation; voice as interpretation: the search for meaning through careful analysis; and finally, voice discerning other voices: the creation of a final, authentic portrait (LawrenceLightfoot \& Davis, 1997).

As the researcher and portraitist, my involvement in this study is contextualized particularly by my professional experiences. My extensive teaching experience at Canadian colleges and universities has afforded me the chance to develop a multifaceted and situated understanding of the challenges and successes of the multilingual international students whom I have worked with. I have learned through first-hand observation and communication with multilingual international students about the impact of the prevailing discourses of deficit that equate non-native proficiency with intellectual and cultural inferiority. Such discourses neglect the influence of the sociocultural environment on the students' abilities to act. As a result, my main objective in this study is to cast a different light on the participating students' experiences by approaching them from a perspective of agency (Tavares, 2021c).

\section{Setting and Participants}

River University, founded in 1959, is the pseudonym for a large, research-oriented university with two campuses in Ontario, Canada. The smaller campus of the two is known specifically for its bilingual profile, offering courses in French and English. I will refer to the smaller campus as "Brook" hereafter, while using River University for the large, main campus. According to River University's website, the university also had two international campuses. Both River's main and Brook campuses are considered in this study. From the university's website, the following figures were also available regarding its population and international affiliations as of the time of the study: approximately 45,000 undergraduate students; 5,000 graduate students; 6,000 international students from around 178 countries; 280 international university partners; and 7,000 faculty and staff.

The recruitment of participants consisted of an invitation forwarded to an international students-related group associated with River University on Facebook. The invitation explained the purpose of the study and offered participants the chance to share their experiences with the researcher. Participants who wished to participate were accepted on the basis of being (1) an international student with a study permit and (2) a multilingual speaker for whom English was a second language. Both international and exchange students were considered. Fourteen participants responded to the invitation. Since the purpose of the study was to understand lived 
experience in detail, only three participants were chosen so that the researcher could focus on the richness of each participant's experience.

Information on the participants is presented in Table 1 below. The languages in each of the focal participants' multilingual repertoires are organized in descending order from the strongest language first, as identified by the participants themselves. A significant difference in time spent at the institution can be observed between the participants. Such a difference was taken as an opportunity to understand one participant's overall experience in more detail and to examine how prolonged acculturation may have impacted the participant's retrospective understanding of the early stages of his own academic journey. Informed consent was obtained from participants through a consent form pre-approved by the university's research ethics office. Pseudonyms are used for all participants.

\section{Table 1}

\begin{tabular}{|c|c|c|c|c|c|c|}
\hline Participant & $\begin{array}{l}\text { Country } \\
\text { of origin }\end{array}$ & Age & Gender & $\begin{array}{l}\text { Program of } \\
\text { study }\end{array}$ & $\begin{array}{c}\text { Time at River } \\
\text { at time of } \\
\text { study }\end{array}$ & $\begin{array}{l}\text { Multilingual } \\
\text { repertoire }\end{array}$ \\
\hline Julie & France & 19 & Female & $\begin{array}{c}\mathrm{BA} \text { in } \\
\text { International } \\
\text { studies }\end{array}$ & 4 months & $\begin{array}{l}\text { French, } \\
\text { English, } \\
\text { Spanish, } \\
\text { German, } \\
\text { Latin }\end{array}$ \\
\hline Fernando & Colombia & 22 & Male & $\begin{array}{c}\text { BA in } \\
\text { Criminology }\end{array}$ & $\begin{array}{c}3 \text { and a half } \\
\text { years }\end{array}$ & $\begin{array}{l}\text { Spanish, } \\
\text { English, } \\
\text { Portuguese, } \\
\text { French, } \\
\text { ASL }\end{array}$ \\
\hline Lee & $\begin{array}{c}\text { Macau, } \\
\text { China }\end{array}$ & 24 & Male & $\begin{array}{c}\text { BA in } \\
\text { Linguistics }\end{array}$ & 4 months & $\begin{array}{l}\text { Mandarin, } \\
\text { English, } \\
\text { Cantonese, } \\
\text { Japanese }\end{array}$ \\
\hline
\end{tabular}

\section{Data Collection and Analysis}

Data for this study were collected through interviews and observations. The methodological approach to observing the setting may be better seen as that of a complete observer. Kawulich (2005) characterized this approach as one normally unobtrusive and unknown to those in the research site. To guide and log the observations, a general field note template was developed based on the observation guidelines proposed by Merriam (1998). The observations focused specifically on the physical and sociocultural environment of River University and the activities as well as interactions taking place in public spaces, such as the library, cafeteria, student lounges, and the overall architecture of campus. Observations were conducted to develop a contextual understanding of the setting, particularly in terms of situating the places which the participants mentioned in their interviews. In total, 20 field notes were completed.

Additionally, four interviews were recorded with each participant. The interviews were semi-structured in nature. Richards (2009) defined a semi-structured interview as "one where the interviewer has a clear picture of the topics that need to be covered (and perhaps even a preferred order for these)" (p. 186) and yet is prepared to cover unexpected topics considered important by the participants. Topics discussed included, but were not limited to, academics, language, culture, emotions, spirituality and religion, finances, and work. Each interview lasted 
approximately 60 minutes. The analysis of interview data was thematic in nature. The process consisted of transcribing the interviews and reading the content multiple times. Subsequently, units of the text (e.g., words, sentences, questions and answers, pauses) were coded thematically by ascribing more elaborate descriptors to those units. Finally, codes were organized into broader categories that emerged organically or were pre-established based on the research questions and the theories guiding the study (Creswell, 2013).

A process of description was employed to analyse the observations. Marvasti (2013) explained that the primary purpose of observations in qualitative research is to aid the researcher in later describing the setting in which the research was conducted, so as to convey the physical and social environment to the audience. Yet, even the act of describing a setting should be considered a process of analysis because the researcher, intentionally or otherwise, makes decisions as to which elements are included in the description and how they are explained (e.g., at what length and order). As Emerson (1988) elaborated, "what is included or excluded is not determined randomly; rather, the process of looking and reporting are guided by the observer's implicit or explicit concepts that make some details more important and relevant than others" (p. 20). The observations were rewritten from the field notes in descriptive form.

\section{Findings}

The findings are presented below in three individual portraits. The titles in each portrait are intended to capture the essence of each student's experience in relation to individual agency. All portraits are based on interweaved data from interviews with the participants and observations conducted by the researcher in order to develop a more unified, fluid, creative, and multifaceted perspective for each portrait.

\section{Julie: Recreating Meanings}

Julie came to River University through an exchange program facilitated by another university in Canada. Once again, Julie found her thirst for self-discovery and growth leading her to a new terrain. The impetus behind her arrival at the smaller of River University's two campuses, namely Brook, was her desire to improve her proficiency in the English language. At her sending institution, she had encountered few opportunities to speak English systematically since her undergraduate program was completely in French. The exchange to Brook was inevitably a much-anticipated adventure. Fortunately, Brook's campus could not be more aesthetically inviting. The campus derived its organic beauty from the surrounding nature. The red maple and blue beech trees decorated the land adjacent to the only paved path that connected the entrance of campus to the main building. Ivy vines covered the old brick walls of the main building, and from a certain angle, this outlook looked like an image from a postcard.

However, the optics of beauty on the outside helped hide the chronic emptiness of the inside. Most students from Brook lived off campus with their families and contributed minimally to creating a socially stimulating atmosphere on the premises. The campus was located in a suburban area and the nearest grocery store, shopping mall, and subway station were only accessible by an infrequent bus that rarely arrived on time. The campus cafeteria closed at $7 \mathrm{pm}$, after which the noise of vehicles passing on the nearby highway would replace the pronounced silence in the hallways. The other international students whom Julie met in the dormitory were also French speakers. As a result, her chances of speaking English consistently were, again, low. She met many other English-speaking students in her courses, but conversational interactions in the classroom were brief and controlled. Following the lectures, the local students would rush over to the bus stop in an attempt to avoid the tedious and 
awkward student lounge where the pool table stood untouched. "Canadian students don't need new friends," was Julie's conclusion after problematizing their absence.

Despite her growing disappointment, Julie could not afford to miss out on this unique chance to improve her English in an English-speaking city. After all, as an exchange student, she knew that her stay at Brook was temporary. In the absence of meaningful opportunities to practice English by socializing with local Anglophone students, she explored possibilities with the international student office on campus. On her first visit, she came across and signed up to volunteer at the upcoming "Brook Open House," an event in which high school students visited the campus to learn more about academics there. On the day of the event, she helped the team set up tables and posters, and later had the chance to chat with visiting students in English. Nevertheless, the open house only took place once a semester and Julie clearly wished for more. She recalled that the international student office had circulated an email among international students in which an invitation was made available for them to participate in a psychology research study. After exchanging emails with the researcher, she had scheduled the first interview.

The researcher offered Julie the option to participate in the study in French. However, Julie unhesitatingly opted for English, even though she was nervous to engage in such a formal experience in her now second language. To gain what she hoped for out of these interactions, Julie reinvented the meaning of the experience: during the interviews, she positioned herself as a multilingual learner of English rather than a research participant. This meant that, while she found the study interesting, she reconceptualized the interviews as "sites" wherein she could freely develop her English by making mistakes, trying out new expressions, and studying the language used by the researcher. Moreover, she borrowed books written in English from the library and attended plays at one of the theatres downtown. These activities did not replace human interaction, but they increased her overall sense of satisfaction, as she reported in the interviews.

Julie never reported having difficulty with a particular skill or aspect of the English language. In other words, her desire to improving her sufficiently advanced proficiency was really to speak more in English. When she did receive feedback on her writing from any of her professors, she would very clearly understand the rationale behind it and incorporate the change into her multilingual repertoire. Such an ability of hers stemmed from her former education in France. By the time she finished high school, she had formally learned some German, Spanish, and Latin. Through these learning experiences, she developed a structural knowledge of language that now mediated her understanding of new linguistic content. In all of her time at Brook, Julie made only one appointment at the career centre on campus - the place where she could receive feedback on her writing. Overall, the academic experience at Brook contributed to the enhancement of her English, though not in the manner she had originally hoped it would have.

When the move-out day approached, Julie left Brook with mixed feelings. The intense disappointment which she felt was behaviourally undisguisable-she embodied it. She had hoped to find socially active student clubs and to form genuinely meaningful friendships with local students. In a way, she expected to experience the life of an international student as pictorially stereotyped on study abroad posters, where students are shown ziplining and hiking together in nature. However, her individual effort could not alter the structural configuration of the community: its small size, withdrawn crowd, and secluded location. She believed her proficiency in the academic register of English had progressed the most, but by no means had she seen comparable progress in her social life. "It's very lonely in here," was the epitaph Julie whispered of Brook as she left it. 


\section{Fernando: Learning from the Past}

Studying at River University was a novel experience for Fernando, a multilingual international student from Colombia. Living in Canada, on the other hand, was nothing new. His experiential familiarity with Canada stemmed from the several months he had spent as a student in an English for Academic Purposes (EAP) program at a private college in Greenville, the pseudonym for a small town in Ontario. The year was 2014, when Fernando, being 17 years old, had arrived in Canada a few months following his long-awaited high school graduation in Bogotá. At first, Fernando's parents were hesitant to support his choice of studying abroad, since he was the only child. However, their disquietude greatly subsided with the emotional and material support they received from Fernando's aunt, who lived in Greenville at the time. During his entire scholastic journey in Greenville, he would be housed with his aunt.

While in Greenville, Fernando's social life was sustained largely through social and cultural activities programmed by the college. After class, the events coordinator would guide the international students through town to facilitate their exposure to Canadian culture. Fernando initially appreciated the structured opportunity to diversify his experience as a multilingual international student in Canada; yet, with the passing of time, he felt increasingly more only superficially connected to the local community. For him, social life had become a "bubble" which he could not break from. There were no events designed for him to meet local students of his own age and to practice the language naturalistically. Every interaction felt scheduled. Essentially, he believed that the college oversimplified the complexity of the transnational experience. Several months later when Fernando returned to Bogotá, he began thinking about university, but hoped to avoid the overwhelming sense of uniformity which had informed his former experience in Greenville.

Fernando returned to Canada in the fall of 2015 to begin his undergraduate studies at River University. In his first year, he was overcome with stress. In his first week of the semester, he attended five different classes. The demands and expectations of each course were such that he started having serious doubts about his capability to succeed. "I left one class in panic and thought I'm not gonna be able to do this," he recalled after imagining all five courses as a single undertaking. His fear of underperforming was rooted in his academic unpreparedness as well as his first linguistic contact with university teaching. Akin to many first-time students, whether international or domestic, he had not received any formal training in how to develop effective learning skills for the academic experience. In one large introductory class, his anxiety would not seem to pass: "the instructor spoke so fast that I didn't know whether I should type the notes or listen to him speaking," he explained.

In his first semester, Fernando plugged himself into the international student network at River. The new circle of friends became an unmatched source of support. The lecture halls felt intimidating, alienating, and cold with their stationary chairs, where he found himself surrounded by different unfamiliar faces each week. Contrastingly, the student lounge on the first floor of the dormitory was much more welcoming. Unlike in the classroom, he could stay around for as long as he wished. In conversation with likeminded peers who were also firsttime multilingual international students at River, he could validate his concerns and challenge his fears about the academic experience. The camaraderie he found in that space translated into friendships that transcended the walls of culture and language. From the growing time he spent with the group, he learned that his apprehension was not only natural, but also likewise felt among his peers.

The past experience in Greenville produced in Fernando a perspicacity about what being a multilingual international student could mean. In his experience, being positioned as an ESL student equated to being an outsider in the eyes of the local community. He disapproved of the ways he perceived others to see his potential: inferior language, temporary investment in Canadian society, and a lack of independence signalled through the handholding exercised by 
the private college through the EAP program. For this reason, when Fernando joined River, he strategized accordingly. One of his introductory courses had a seminar attached to it. The seminar was subdivided into two distinct groups that met on different days: the ESL seminar and the "regular" one. Despite his official status as an international student who had completed a language proficiency test for admission, he opted to reject affiliation to the ESL seminar. As it will be elaborated in the discussion, his choice signified an act of resistance against the physical and sociocultural separation from the local community which, formerly, he had negatively experienced in Greenville.

\section{Lee: Calculating Risks}

Lee came to Canada to attend River University following several years of study in the United States. Prior to moving to the US, Lee's proficiency in the English language was still in development. His English language education in Macau had consisted of learning the language through the translation method. The impact of such a pedagogical experience was twofold: first, and more generally, Lee needed more linguistic preparation to study abroad in English. Second, while his writing skills saw the most relative progress, his oral language skills remained rudimentary by the end of grade nine. As a result, despite the excitement he felt about studying overseas, the first few years of his journey as a high school student in New York were characterized by despondency. His language proficiency, still in development, affected him both socially and academically, as he lagged behind his peers in school.

The obstacles along the way never stopped Lee from believing in his potential. Language, however, was not the only barrier he needed to overcome in order to move forward. He particularly disapproved of the cold, blurry, and snowy days of New York's long winter, which kept residents indoors and interfered with his chances of meeting new people. He was gregarious and inquisitive, but his interactional attempts to initiate conversations with local New Yorkers only resulted in brief and awkward exchanges - at the gym, bus stops, and coffee shops. Years of superficial contact with locals directly informed his view of New York: "In the east coast, people are more... [socially] conservative. I think of the east coast like that. When I was in New York, people were more like, sort of checked out," he explained. As opportunities for naturalistic conversation with locals were unavailable, Lee resorted to YouTube to learn the language. He would mimic the pronunciation of English speakers and memorize the idiomatic expressions they used. To improve every other aspect of his experience, however, he devised a more intricate plan.

The conclusion of high school left the doors open for Lee to make a fresh start. This time, he took another important step by leaving the east for the west again. The challenges he faced throughout high school in New York contributed to his growth as person, despite the emotional imprint they left on him. He was now instilled with an unparalleled bravery, ambition, and volition. He matriculated at a college in Santa Monica, California, where the allyear-round warm sunshine would replace the gloomy days of New York. As a multilingual user of English, his acceptance to the college was only officialized after he passed the TOEFL test. "I thought I had failed, but I passed," he jocosely confessed. Once again, Lee's arrival in California was viscerally reminiscent of when he arrived in New York: he knew nobody, had a single suitcase, and many expectations in place.

Life in Santa Monica was so socially fulfilling for Lee that college itself became extraneous. While he was genuinely interested in the computer science program, he preferred to seize on the opportunities to socialize with both local and international students at the college. His new friendships extended beyond campus and led him to the beaches of Santa Monica, where he played team sports after class. He enjoyed three fulfilling years on the west coast before he came to southern Ontario to begin his undergraduate studies as a transfer student at River University. The passionate investment in reconstructing the social life he had missed out 
on in New York positively influenced the development of his conversational skills in English. On the other hand, his proficiency in the academic register of English remained dormant. As a result, his first semester at River was immensely challenging. The low grades he received only amplified his plight, but he responded by seeking help.

Lee identified that his challenges were related to reading and writing in English, and strategized accordingly. He made a series of appointments with his teaching assistants (TAs) to get clarification and guidance. Besides the scheduled meetings at the office, Lee intercepted his TAs on the way to the classroom to ask as many questions as the pace of his TAs allowed. His incessant quizzing led one of his TAs to feel irritated: "the TA isn't that patient. Because I ask a lot of questions. I asked her a lot of questions [and] she's got annoyed about that," he clarified while highlighting his role in the outcome of the event. In general, Lee felt disengaged from learning. He missed California, disliked Ontario, but had to keep moving forward. He was deeply aware of how hard his parents had been working in order to pay for his tuition. Passing his courses felt then like a great mission. But he did pass.

An appointment at River's writing centre was an additional attempt to ameliorate the challenging academic situation. Despite the good intention, throughout the appointment with one of the tutors, he felt conflicted. The extensive journey he had previously navigated in the United States afforded him the opportunity to develop his identity in ways that brought him an enormous sense of autonomy. Discovering himself away from the direct influence of family and the expectations of the Macau community had two important implications for his identity. He not only became better aware of the cultural representations of Macau people abroad, as an out-looker, but also had more control over the choice of experiences he wished to participate in. In this sense, he saw his identity as a product of an individual, rather than collective, effort. At the writing centre at River, Lee felt as though this progress was under threat when he saw himself surrounded by other Asian multilingual students. Consequently, protecting his carefully constructed identity held more weight than improving his English, which meant he never returned to the writing centre again so as to dissimilate himself from other Asian students.

\section{Discussion and Conclusion}

This paper offered a contextualized and balanced presentation of the experiences of three multilingual international students at a Canadian university. This investigation was guided by two concerns: identifying and understanding, first, the challenges the students encountered, and second, the ways in which the students responded to and overcame them. Prior to discussing the answers to such points, it is essential to highlight that the manner with which the students conceived of their experiences at the time of the study was informed directly by the outcomes of their past experiences. As such, the students' engagement in many of their present experiences may be seen as attempts to revert the meaning of previous experiences where their needs and expectations had remained unmet. This "imprint" is more evident in Fernando's and Lee's portraits, as the two students approached their social experiences at River University under the influence of the negative feelings which they had experienced as outsiders in the absence of interaction with locals before arriving at River.

The challenges should be considered as interrelated, and primarily as linguistic, academic, and social in nature. When it comes to language-related experiences, most of these can hardly be categorized as challenges per se. Julie had an advanced level of proficiency in the language prior to coming to Brook. When she did make an appointment to receive feedback on her writing, her impetus was to actually continue to do well in the course - that is: to maximize her potential rather than to "fix" any language issues she had. As for Fernando, his understanding of his challenges originated from misperceptions based on fear, particularly as in potentially misunderstanding his instructors in their use of a "fast" and specialized register of the language. Differently, Lee's proficiency in English remained the same for most of his 
time as an international student. Therefore, he could not succeed academically and socially during his initial time in the United States when compared to his local peers. Life in California afforded him the development of cultural forms of the language. Yet, his "academic" English remained stagnant, which later posed tremendous risks to his academic progression at River. In particular, Lee had difficulty with academic reading and writing.

The three students were also impacted by academic and social challenges, though to noticeably varying degrees. Fernando and Lee came to River unprepared for academic learning from not having acquired the learning skills needed for academic success. As first-time students, Fernando's and Lee's unpreparedness quickly rendered their higher learning experiences trying. Challenges in the social domain of experience held equal, or perhaps even more, weight than those of a linguistic or academic nature. The social challenges of the students were characterized by the lack of opportunities for meaningful and continuous interaction principally with local students, and to a lower degree, even with other multilingual international students - as was the case with Julie. The unavailability or superficiality of social interaction translated into feelings of isolation, frustration, and boredom. Contrastingly, Fernando's social connection to fellow multilingual international students brought about a strong sense of belonging and support. Although Fernando formed such connections in his first semester at River, it is important to note that, overall, he had spent more time at the university and, consequently, had more time to reflect on his experiences.

The students' experiences demonstrate that meaningful social interaction is central to a sense of overall satisfaction. Nevertheless, forming social bonds is complex and takes time, even more so when in a different linguistic and cultural context. Accordingly, Ammigan (2019) has argued that universities share responsibility in facilitating interaction between multilingual international students and their local peers. Ammigan (2019) proposes that, for such interactions to offer international students the greatest chances of social success, "initiatives must accompany both curricular and extracurricular programs and occur in social settings inside and outside of the classroom" (p. 277). Research indicates that local students may also be interested in deeper intergroup contact; however, there is an expectation that universities should lead such initiatives (Arthur, 2017; Tavares, 2021a). Nevertheless, intergroup interaction, or the lack thereof, has much more significant implications for multilingual international students. Interactions have the potential to afford multilingual international students the (further) development of language proficiency, social networks, and cross-cultural learning (Tavares, 2020, 2021b). Hence their importance for the feeling of overall satisfaction.

The second concern in the paper relates to how the three students exercised agency and remained academically buoyant. Indeed, each portrait illustrates clearly that the students strategized actively in response to the challenges before them. The absence of meaningful social interaction led Julie to search out for alternative ways to meet her linguistic and social needs, such as in volunteering in campus events and research studies. This kind of agency-focused behaviour is what Bandura (2006) defined as intentionality: not only desiring, but also having the vision of how to achieve a goal. On the basis of his institutional status, Fernando was expected to attend an ESL seminar, but refused to join it after having felt constrained by the ESL label assigned to him in the past. As for Lee, he resorted to his TAs and the writing centre for assistance, but quickly abandoned the latter due to an identity conflict. Lee's agency in particular challenges the assumption that Asian students are passive and avoid insistent behaviour that would "annoy" authorities (Harper \& Chen, 2018; Zhu \& O'Sullivan, 2020). As Tran and Vu (2018) have voiced it, agency can be seen in/as resistance when international students defy normative behaviour. As the portraits suggest, the reasons for this are complex and do not originate simply from an imagined, inherent tendency for disruption that multilingual international students are thought to possess.

Agency in the form of resistance often reveals areas where structural issues persist. Oropeza et al. (2010) also documented instances in which minority-language multilingual 
students refrained from using support services at their university because such services did not meet their linguistic and academic needs. Those services were constructed around ideologies of deficit for multilingual students, but not for local, native-speaker students. Therefore, it is essential to approach the multilingual international student experience from an emic perspective - that is, from the students' perspectives - and to investigate the ways in which the sociocultural environment replicates institutional barriers and inferior labels for multilingual international students. As the authors argued, "services that construct students in what are perceived to be deficit labels may end up leading students to resist such labels, thus excluding the very students they wish to serve" (Oropeza et al., 2010, p. 228).

Academic buoyancy was conceptually employed to help identify the means by which the students responded to their setbacks. Lee's academic performance was at risk due to his low grades on course papers. Low grades, coupled with his growing dissatisfaction with the experience at River-which reminded him of his time in New York-only exacerbated the problem. However, he concentrated on the hard work of his parents in order to devise a plan for action. While Lee found support in the imagined presence of family, Fernando found community among other multilingual international students. The anxiety Fernando felt about underperforming gradually diminished as his feeling of connectedness increased. Emotional and social support contributed to how the students made sense of and dealt with their challenges. As for Julie, her tenacity to make the most out of her likely only experience in an Englishmedium environment also motivated her to overcome the frustration she felt in relation to the unavailability of peer interaction.

In revisiting both challenge and success, a critical attention to the institutional and sociocultural contexts remains indispensable. This is perhaps the most important point from this study when it comes to understanding multilingual international student agency and, by extension, success. The environment determines many of the possibilities to act, both physically and socially. Course seminars, support services, student orientations, and cultural events divided on the basis of language or nationality reflect policies that create limitations for multilingual international students to overcome their challenges and meet their needs (Jones, 2017; Tavares, 2021a). This was most apparent in Julie's portrait - despite her ongoing effort to find "openings" to socialize and practice the language, she simply could not bypass the physically, socially, and institutionally inflexible configuration of Brook's campus. Universities must continue to consider their role not only in perpetuating challenges, but also in preventing multilingual international students' agentive efforts from coming into effect.

In conclusion, a few recommendations are worth mentioning. First, more support is needed to adequately prepare incoming multilingual international students for higher learning. Initiatives focused on the development of learning skills and of academic English should be embedded in course planning and delivery. Furthermore, in the first year, especially, social connections are essential to help multilingual international students make sense of their experiences (Tavares, 2019). As such, rather than being separated on the basis of first language, seminars attached to introductory courses should be linguistically designed in a way that accommodates all students, thus maximizing and diversifying the potential for interaction. Instructors and teaching assistants are therefore in a unique position to contribute to the improvement of social interaction between international and local students, and by extension, to their academic success (Zhou et al., 2017).

Lastly, multilingual international students need to be more aware of the cultural and physical arrangements of their host institutions prior to arrival. Online research can provide some information in regard to campus location and transportation, for example. Additionally, international students and international offices need to work in collaboration prior to the students' arrival. However, these recommendations are not meant to exempt the university from its responsibility to develop initiatives to welcome international students. Of course, these recommendations should be considered carefully in light of the experiences of the small sample 
in the study, with distinct linguistic, academic, social, and psychological backgrounds. Moreover, the findings reflect experiences based on the students' perceptions and the researcher's observations. Therefore, the findings are not intended to be generalizable, although they may still be of relevance to other educational contexts.

\section{References}

Ahearn, L. M. (2001). Language and agency. Annual Review of Anthropology, 30(1), 109-137. Ammigan, R. (2019). Institutional satisfaction and recommendation: What really matters to international students. Journal of International Students, 9(1), 262-281.

Anderson, T. (2020). News media representations of international and refugee postsecondary students. The Journal of Higher Education, 91(1), 58-83.

Arthur, N. (2017). Supporting international students through strengthening their social resources. Studies in Higher Education, 42(5), 887-894.

Bandura, A. (2006). Toward a psychology of human agency. Perspectives on Psychological Science, 1(2), 164-180.

Bartlett, T., \& Fischer, K. (2011, November 3). The China conundrum. The New York Times.

Chapman, T. (2005). Expressions of "voice" in portraiture. Qualitative Inquiry, 11(1), 27-51.

Choi, J. Y. (2015). Reasons for silence: A case study of two Korean students at a US graduate school. TESOL Journal, 6(3), 579-596.

Choudaha, R. (2017). Three waves of international student mobility (1999-2020). Studies in Higher Education, 42(5), 825-832.

Creswell, J. W. (2013). Qualitative inquiry \& research design: Choosing among five approaches. Sage.

Emerson, R. (1988). Contemporary field research: A collection of readings. Waveland Press.

Fell, E. V., \& Lukianova, N. A. (2015). British universities: International students' alleged lack of critical thinking. Procedia-Social and Behavioral Sciences, 215, 2-8.

Friedenberg, J. E. (2009). Treating international students' language as a resource rather than a deficit. In M. S. Andrade \& N. W. Evans (Eds.), International students: Strengthening a critical resource (pp. 163-169). Rowman \& Littlefield Education.

Government of Canada. (2018). Stay in Canada after graduation. https://www.canada.ca/en/immigration-refugees-citizenship/services/studycanada/work/after-graduation.html.

Harper, J., \& Chen, H. J. (2018). Group dynamics and student participation in a Chinese setting: Teacher and observer perspectives. Journal of English Language Teaching \& Linguistics, 3(1), 21-40.

Heng, T. T. (2018). Exploring the complex and non-linear evolution of Chinese international students' experiences in US colleges. Higher Education Research \& Development, 37(6), 1141-1155.

Huang, J., \& Cowden, P. (2009). Are Chinese students really quiet, passive and surface learners? A cultural studies perspective. Comparative \& International Education, 38(2), 75-88.

Jones, E. (2017). Problematising and reimagining the notion of 'international student experience'. Studies in Higher Education, 42(5), 933-943.

Kawulich, B. B. (2005, May). Participant observation as a data collection method. Forum Qualitative Sozialforschung/Forum: Qualitative Social Research, 6(2).

Kim, T. Y., Kim, Y., \& Kim, J. Y. (2018). A qualitative inquiry on EFL learning demotivation and resilience: A study of primary and secondary EFL students in South Korea. The Asia-Pacific Education Researcher, 27(1), 55-64.

Lawrence-Lightfoot, S., \& Davis, J. H. (1997). The art and science of portraiture. Jossey-Bass. 
Martin, A. J., \& Marsh, H. W. (2008). Academic buoyancy: Towards an understanding of students' everyday academic resilience. Journal of School Psychology, 46(1), 53-83.

Marvasti, A. (2013). Analysing observations. In U. Flick (Ed.), The SAGE handbook of qualitative data analysis (pp. 354-366). Sage.

Merriam, S. B. (1998). Qualitative research and case study applications in education. JosseyBass Publishers.

Muramatsu, C. (2013). Portraits of second language learners: Agency, identities, and second language learning [Unpublished doctoral dissertation]. University of Iowa.

Oropeza, M. V., Varghese, M. M., \& Kanno, Y. (2010). Linguistic minority students in higher education: Using, resisting, and negotiating multiple labels. Equity \& Excellence in Education, 43(2), 216-231.

Richards, K. (2009). Interviews. In J. Heigham \& R. Croker (Eds.), Qualitative research in applied linguistics: A practical introduction (pp. 182-199). Palgrave MacMillan.

Ruble, R. A., \& Zhang, Y. B. (2013). Stereotypes of Chinese international students held by Americans. International Journal of Intercultural Relations, 37(2), 202-211.

Shapiro, S. (2014). "Words that you said got bigger": English language learners' lived experiences of deficit discourse. Research in the Teaching of English, 48(4), 386-406.

Tavares, V. (2019). A review of peer interaction and second language learning for ELL students in academic contexts. Canadian Journal for New Scholars in Education/Revue Canadienne des Jeunes Chercheures et Chercheurs en Éducation, 10(2), 113-121.

Tavares, V. (2020). Multidisciplinary perspectives on international student experience in Canadian higher education. IGI Global.

Tavares, V. (2021a). International students in higher education: Language, identity, and experience from a holistic perspective. Lexington Books.

Tavares, V. (2021b). "The course is no longer great": The need for socially meaningful online instruction for international students. In R. Chan, K. Bista, \& R. Allen (Eds.), Online teaching and learning in higher education during COVID-19: International perspectives and experiences (pp. 93-106). Routledge.

Tavares, V. (2021c). Theoretical perspectives on international student identity. Journal of Comparative \& International Higher Education, 13(2), 83-97.

Tran, L. T., \& Vu, T. T. P. (2018). 'Agency in mobility': Towards a conceptualisation of international student agency in transnational mobility. Educational Review, 70(2), 167187.

Vitanova, G., Miller, E. R., Gao, X., \& Deters, P. (2015). Introduction to theorizing and analyzing agency in second language learning: Interdisciplinary approaches. In P. Deters, X. Gao, E. R. Miller, \& G. Vitanova (Eds.), Theorizing and analyzing agency in second language learning (pp. 1-13). Multilingual Matters.

Wu, G., Feder, A., Cohen, H., Kim, J. J., Calderon, S., Charney, D. S., \& Mathé, A. A. (2013). Understanding resilience. Frontiers in Behavioral Neuroscience, 7, 1-15.

Xiao, M. (2021). Chinese international graduate students at Canadian universities: Language barriers, cultural identities and perceived problems of engagement. International Journal of Inclusive Education, 26, 1-18.

Zhou, G., Liu, T., \& Rideout, G. (2017). A study of Chinese international students enrolled in the Master of Education program at a Canadian university: Experiences, challenges, and expectations. International Journal of Chinese Education, 6(2), 210-235.

Zhu, H., \& O'Sullivan, H. (2020). Shhhh! Chinese students are studying quietly in the UK. Innovations in Education and Teaching International, 1-10. 


\section{Notes on Contributor}

Vander Tavares is currently a Postdoctoral Research Fellow in the Faculty of Education at Høgskolen i Innlandet (Inland Norway University of Applied Sciences). His major research interests include internationalization of higher education and the international student experience; the intersection of language, culture, and identity; and second language acquisition. $\mathrm{He}$ is the editor of Multidisciplinary Perspectives on International Student Experience in Canadian Higher Education (IGI Global) and the author of International Students in Higher Education: Language, Identity and Experience from a Holistic Perspective (Rowman \& Littlefield/Lexington Books).

Manuscript received April 20, 2021

Final revision received August 2, 2021

Accepted August 6, 2021 